Int. J. Electrochem. Sci., 15 (2020) $7483-7492$

International Journal of

ELECTROCHEMICAL

SCIENCE

WWW.electrochemsci.org

\title{
Remarkable Enhancement in Electrochemical Performances of La-Mg-Ni-based Alloy Decorated with the Reduced Graphene Oxide Supported Cobalt
}

Dongyuan Huang ${ }^{1}$, Bing Wei ${ }^{1}$, Peilin Qing ${ }^{2, *}$,Wenzheng Zhou ${ }^{1,2}$, Haizhen Liu ${ }^{1,2}$, Jin Guo ${ }^{1,2}$, Zhiqiang Lan $^{1,2, *}$

${ }^{1}$ Guangxi Novel Battery Materials Research Center of Engineering Technology, Guangxi Key

Laboratory of Processing for Non-ferrous Metallic and Featured Materials, Guangxi Colleges and

Universities Key Laboratory of Novel Energy Materials and Related Technology, School of Physical

Science and Technology, Guangxi University, Nanning 530004, P. R. China

${ }^{2}$ Guangxi Colleges and Universities Key Laboratory of structure research and performance developme nt of rare earth alloy, School of Materials Science and Engineering, Baise University, Baise 533000, P.

R. China

*E-mail: plqing110@163.com (Peilin Qing) and 1_zq1100@163.com (Zhiqiang Lan)

doi: $10.20964 / 2020.08 .26$

Received: 8 April 2020 / Accepted: 22 May 2020 / Published: 10 July 2020

A reduced graphene oxide supported cobalt $(\mathrm{Co} @ \mathrm{G})$ was synthesized via a wet-chemical method and was then introduced into a $\mathrm{La}_{0.7} \mathrm{Mg}_{0.3}\left(\mathrm{Ni}_{0.85} \mathrm{Co}_{0.15}\right)_{3.5}$ alloy (designated as $\mathrm{La}-\mathrm{Mg}-\mathrm{Ni}$ ) by means of mechanical alloying. Experimental results indicated that the La-Mg-Ni alloy electrodes decorated with Co@G nanocomposites exhibited excellent electrochemical performance. At a discharge current density of $1200 \mathrm{~mA} / \mathrm{g}$, the high rate dischargeability $\left(H R D_{1200}\right)$ of the undecorated alloy electrode was $59.8 \%$. This value increased to $82.3 \%, 84.7 \%$, and $70.7 \%$, respectively, when the alloy electrode was decorated with $x$ wt.\% $(x=3,6,9)$ Co@G nanocomposites, respectively. The exchange current density $\left(I_{0}\right)$ and the limiting current density $\left(I_{\mathrm{L}}\right)$ were also enhanced under the catalytic action of the Co@G nacocomposites. The electrode decorated with the 6.0 wt.\% Co@G nanocomposite exhibited the best electrochemical performance. The improvements in electrochemical performance of the $\mathrm{La}-\mathrm{Mg}-\mathrm{Ni}$ alloy electrodes are attributed to the synergistic catalytic action of graphene and $\mathrm{Co}$, thereby facilitating the electron transport and shortening the ion transportation paths in the alloy electrodes.

Keywords: Battery; Electrochemical performance; Dynamics; Graphene; Rare earths 
(C) 2020 The Authors. Published by ESG (www.electrochemsci.org). This article is an open access article distributed under the terms and conditions of the Creative Commons Attribution license (http://creativecommons.org/licenses/by/4.0/). 